\title{
Catolicismo, sexualidade e AIDS: pertencer sem ser fiel
}

\author{
Carolina Teles Lemos \\ Doutora em Ciências Sociais e da Religião (Universidade Metodista de São Paulo) \\ Professora titular da Pontifícia Universidade Católica de Goiás \\ Goiânia, Brasil \\ cetelemos@uol.com.br
}

Resumo Consideramos neste artigo a intrincada relação entre: a) a dinâmica adquirida pelo avanço do HIV na sociedade atual, b) as diferentes concepções de sexualidade que significam as práticas sexuais das pessoas e a adesão ou não às proposições quanto aos cuidados necessários à prevenção da AIDS, c) as permanências e mudanças ocorridas no campo religioso, em que se observa a presença de um discurso normatizador da sexualidade, principalmente a partir da Igreja Católica, d) a característica da centralidade do indivíduo como instância de referência na cultura atual. A partir daí, analisamos como esses aspectos são articulados na maneira como os portadores de HIV significam essa realidade.

Palavras-chave: Igreja Católica, sexualidade, AIDS, indivíduo, campo religioso.

$\mathrm{N}$

ESTE ARTIGO NOS PROPOMOS PENSAR sobre a estreita relação existente entre ideários religiosos oriundos do catolicismo sobre a sexualidade e a incidência desse ideário sobre as vivências da sexualidade na atualidade. Entendemos que as mudanças ocorridas no campo religioso e na cultura mais geral incidem diretamente nas concepções e nas vivências da sexualidade Ou seja, se o ideário apresentado pela Igreja Católica referente à sexualidade perde peso diante da ênfase dada pelos indivíduos às suas escolhas pessoais, pode-se resultar em configurações e significações das relações com características diferentes das pleiteadas pelas instituições religiosas tradicionais.

Consideramos, portanto, neste artigo a intrincada relação entre: 1) a dinâmica adquirida pelo avanço do HIV na sociedade atual; 2) as diferentes concepções de sexualidade que significam as práticas sexuais das pessoas e a adesão ou não às proposições quanto aos cuidados necessários à prevenção da AIDS; 3) as permanências e mudanças ocorridas no campo religioso, em que se observa a presença de um discurso normatizador da sexualidade, principalmente a partir da Igreja Católica; 4) a característica da centralidade do indivíduo como instância de referência na cultura atual.

Para efetivar nossa análise, traçaremos um breve panorama sobre as diferentes faces com que a AIDS se apresenta na sociedade atual e nos ateremos, então, nas concepções de sexualidade oriundas da Igreja Católica, bem como sobre a incidência dessas concepções para as pessoas soropositivas e sobre os significados conferidos ao fato de se saberem portadores do HIV. 


\section{AIDS: uma dor com muitas faces}

Entendemos que a epidemia da AIDS (Síndrome da Imunodeficiência Adquirida), causada pelo HIV (Vírus da Imunodeficiência Humana), por ter diferentes características nas diversas regiões do mundo (Leal, 2009), deve ser entendida como "um construto social que se molda dentro do contexto de sistemas sociais, culturais, políticos e econômicos altamente específicos, porém interligados e sobrepostos" (Parker, 1994, p. 18). Embora sejam muitos os aspectos que compõem a dinâmica da AIDS, alguns se sobressaem no desenrolar tanto dos avanços da epidemia como nas formas de seu enfrentamento. Referimo-nos às crenças e práticas sociais que estruturam as relações sexuais. Assim, para entender o caráter e o desenvolvimento da AIDS no Brasil, é necessário ter uma noção das formas como essas crenças e práticas são construídas social e culturalmente. Como o foco de nossa investigação é a inter-relação entre HIV, sexualidade e ideias religiosas, nos ateremos aos discursos da Igreja Católica como elementos presentes nas crenças e práticas referentes a essa temática, bem como às possíveis consequências dos referidos discursos no enfrentamento da AIDS por portadores do HIV.

No que tange à relação sexualidade-HIV, entendemos que as relações sexuais não são simplesmente um conjunto de estímulos biológicos que encontram ou não uma liberação direta, mas sim uma forma de relação social que pode envolver relações de poder, identidades sociais, preconceitos, desigualdades e diferenças entre as pessoas (Giddens, 1992, p. 33). Assim, as desigualdades presentes nessas relações se traduzem em habilidades e capacidades diferenciadas quando, por exemplo, se trata de decidir sobre o uso de preservativos, o que incidirá na possibilidade ou não de adquirir o HIV (Leal, 2009). Como sexo, então, é uma relação de poder, tal qual a classe social e a etnia, uma mulher negra e pobre torna-se mais vulnerável à contaminação. Isto ocorre também com os mais jovens, que têm menos poder nas relações sexuais do que os mais velhos, sem falar nos homo e bissexuais, que continuam sofrendo discriminação (Parker, 2004).

Como a dinâmica da AIDS está intrincada com outros aspectos da cultura, entre eles as relações de gênero, ${ }^{1}$ para entender a expansão e o enfrentamento dessa doença é necessário considerar as permanências ou as mudanças nas configurações dessas relações. Isto porque, em consonância com essas mudanças ou permanências, a epidemia da AIDS adquire novos rumos. Alguns sinais da relação entre as mudanças nas configurações de gênero, sexualidade e AIDS podem ser observados em vários aspectos. Um deles é a antecipação e a aproximação da idade de iniciação sexual entre ambos os sexos. Embora a mudança seja lenta (os homens ainda se iniciam mais cedo), pode-se afirmar que o modelo tradicional - em que os homens são identificados com o sexo ativo, enquanto as mulheres devem se "resguardar" - está mudando aos poucos no Brasil (Leal, 2009). Essa mudança traz consigo desafios no que tange à AIDS, pois a jovem, mesmo sendo alvo de campanhas de prevenção e com preservativos disponíveis, dispensa a proteção porque nem sempre dispõe de um lugar tranquilo para suas práticas sexuais, geralmente feitas com rapidez $\mathrm{e}$ às escondidas.

Se há mudanças nas reconfigurações das relações de gênero e da sexualidade a ela articulada, o conservadorismo nessas relações também incide nos avanços e enfrentamentos do HIV, como se pode perceber, por exemplo, pelo aumento de mulheres portadoras do vírus no Brasil. Um boletim divulgado pelo Programa Nacional de Doenças Sexualmente Transmissíveis (DST)/AIDS, em 2003, informa que a proporção de casos no grupo masculino foi de apenas 1,6 maior do que no feminino. Em 1993, essa proporção era de 3,5. Esse aumento de casos de AIDS entre as mulheres pode ser explicado pelo fato de que, em sociedades - como a nossa - hierarquicamente organizadas com base nas relações de gênero, o sexo feminino é um dos eixos de desigualdade. Isso torna as mulheres mais vulneráveis à doença. Muitas delas têm dificuldades em propor práticas sexuais mais seguras, temendo que seus parceiros questionem o motivo dessa negociação e partam para a violência - o que realmente acontece em muitos casos (Parker, 2004).

Se a AIDS vem se modificando conforme as mudanças e/ou permanências dos significados conferidos a ela, os quais são relacionados aos significados conferidos à sexualidade e às diferentes configurações das relações de gênero, como estão os posicionamentos da Igreja Católica sobre o tema e qual tem sido a recepção e adesão das pessoas portadoras do HIV em relação a esses discursos? Se o $\mathrm{Papa}^{2}$ afirma que

1. A respeito da definição de gênero, acompanhemos o pensamento de Scott (1996, p. 11 e 14), para quem "o gênero é um elemento constitutivo de relações sociais baseado nas diferenças percebidas entre os sexos, e o gênero é uma forma primeira de significar as relações de poder [...]. Ele se refere à oposição homem/mulher e fundamenta, ao mesmo tempo, o seu sentido".

2. Cardeal Javier Lozano Barragan, chefe do Conselho de Saúde do Vaticano, falando em nome do Papa João Paulo Il por ocasião do Dia Mundial da Luta contra a Aids, em 30/11/2004. Informações disponíveis em: <http://www.sistemas. aids.gov.br/imprensa/Noticias.asp? NOTCod=61315>. Acesso em: 1 maio 2010. Esse discurso é uma retomada da Alocução de João Paulo II na IV Conferência Internacional sobre AIDS "Viver, para quê?", promovida pelo Pontifício Conselho para a Pastoral dos Agentes Sanitários, celebrada na Sala do Sínodo do Vaticano em 13, 14 e 15 de novembro de 1989. Disponível em: <http://www.acidigital.com/aids/igreja.htm>. Acesso em: 1 jun. 2010. 
essa doença é uma patologia do espírito, uma imunodeficiência dos valores morais, qual a influência de tal postura do Vaticano e de outros órgãos ou instâncias da Igreja Católica na política de prevenção à AIDS? Como se interpenetram as dinâmicas que regem os avanços da AIDS e as formas de enfrentamento da doença e as mudanças culturais que situam o lugar das ideias religiosas enquanto definidoras da moral social? Buscaremos, nos tópicos seguintes, trazer alguma luz a essas questões.

\section{Catolicismo(s) e sexualidade}

São cinco os subsistemas que coexistem e se articulam no universo sexual brasileiro, e que servem como padrões de referência para os brasileiros na construção e interpretação de suas próprias experiências sexuais: o sistema de gênero patriarcal, o sistema de proibições religiosas, o discurso médico higienista do século XIX, o discurso da ciência moderna do sexo, a ideologia do erotismo (Parker, 1991, p. 15).

O sistema de proibições religiosas é "focado não apenas no corpo e seus atos, mas nas implicações desses atos para a alma". Tal sistema tem origem na tradição católica, e seus valores fundamentais são o casamento, a monogamia e a procriação. Assim, "a conduta sexual que combina com sucesso esses três elementos é compreendida como legítima e aceita dentro da visão católica de mundo"; o contrário é percebido como fora dos limites da "legitimidade e da virtude", entrando em cena a noção de pecado (Parker, 1991, p. 15-16). No entanto, a Igreja Católica, como qualquer outra instituição do gênero, não só não é unívoca em seus discursos sobre a sexualidade, como encerra em seu seio diferentes formas de adesão a seus discursos por parte de seus fiéis.

Não cabe nas dimensões de um artigo a (re)construção de uma sociologia do(s) catolicismo(s), mas necessário se faz pelo menos remeter o leitor à importante literatura que analisa a referida Igreja, como as obras de Brandão (1988), Sanchis (1992), Pierucci (1996), Steil e Herrera (2010), Azevedo (1966, 1969), Azzi (1976), Comblin (1968) que destacam, entre outras coisas, as diferentes formas possíveis de "ser" católico.

Além das diferentes formas possíveis de "ser" católico, devido à própria forma como o catolicismo se compõe internamente, outros aspectos são levantados na análise de tal fenômeno na atualidade, como a autonomia do indivíduo associada à perda do poder da instituição religiosa (Hervieu-Léger, 1993, 1997; Pierucci, 1996). É considerando as diferentes formas de "ser" católico e a centralidade do indivíduo que centraremos nosso olhar sobre a forma como a Igreja
Católica foi construindo seu discurso sobre a sexualidade até chegar à formação de seu posicionamento sobre a AIDS na atualidade.

Existe uma gama de análises já realizadas sobre o processo de construção das ideias cristãs sobre a sexualidade, bem como sobre a inter-relação existente entre elas e as práticas sexuais cotidianas dos(as) fiéis. Dentre essas análises destacam-se as de Flandrin (1985, 1988), Ariès (1985a, 1985b), Foucault (1985, 1993), Duby (1995), Braunstein (1995), Grieco (1991), Kessel (1991), Thomasset (1990), Vecchio (1990), Leclercq (1990), as quais enfatizam os diferentes contextos históricos em que se deu a elaboração do discurso religioso cristão sobre a sexualidade.

Segundo Foucault (1994), o termo "sexualidade" data do início do século XIX. No entanto, o surgimento do termo em data tão recente não significa que essa temática tenha emergido de forma brusca somente neste período.

O uso da palavra foi estabelecido em relação a outros fenômenos: o desenvolvimento de campos de conhecimentos diversos (que cobriam tanto os mecanismos biológicos de reprodução como as variantes individuais ou sociais de comportamentos); a instauração de um conjunto de regras e de normas, em parte tradicionais e em parte novas, e que se apoiam em instituições religiosas, judiciárias, pedagógicas e médicas; como também as mudanças no modo pelo qual os indivíduos são levados a dar sentido e valor à sua conduta, seus deveres, prazeres, sentimentos, sensações e sonhos. (Foucault, 1994, p. 9)

O processo em que se gerou uma visão punitiva da sexualidade nas sociedades ocidentais também é analisado por Foucault (1985), a partir do pensamento de Cassiano, teólogo cristão do século III da era cristã, sobre o combate da castidade. Foucault afirma que, para Cassiano, a fornicação (prática do sexo ilícito) e a gula eram a matriz dos oito espíritos do mal (vícios pecaminosos). Isso porque são dois vícios "naturais", inatos, dos quais a pessoa tem muita dificuldade de se desfazer; ambos implicam a participação do corpo para se formarem e realizarem seu objetivo. Ademais, há entre eles vínculos de causalidade muito direta: é o excesso de alimento que acende no corpo o desejo da fornicação.

A partir dessa compreensão, Foucault afirma que Cassiano elabora uma escala de inter-relação causal entre os vícios: a gula provoca a fornicação. Esta, por sua vez, engendra a avareza e faz nascer as rivalidades que provocam a tristeza e, com ela, a aversão pela vida monástica. A única maneira de superar um desses vícios é a de superar sua causa. Então, o primeiro vício a ser enfrentado pelo monge que deseja se santificar deve ser a gula, razão pela qual se fazem 
insistentes recomendações de jejuns e abstinências. Como não há nenhuma exigência natural para sua manutenção, o vício da fornicação deve ser extinto totalmente através de uma mortificação radical. O processo de sua superação deve passar por diferentes estágios, conforme a classificação feita por Cassiano.

Segundo Foucault (1985), para Cassiano, o progresso do monge no combate à fornicação é marcado pelas seguintes características: (1) quando o monge, estando acordado, não sente desejos da carne, significa que não há mais movimentos da alma que o impelem a esses desejos; (2) quando, mesmo que pensamentos voluptuosos venham a seu espírito, o monge não se detém neles; (3) quando motivações externas não provocam no monge a concupiscência (pode-se passar por uma mulher e olhá-la sem nenhuma cobiça); (4) quando o monge não experimenta, durante a vigília, nem mesmo o mais inocente movimento da carne; quando o espírito de uma conferência ou de alguma leitura trouxer a ideia da reprodução humana, o espírito não se deixará tocar pelo consentimento ao ato voluptuoso, mas considerá-lo como uma fabricação de tijolos ou outra atividade qualquer; (5) o último estágio dessa superação se daria quando, durante o sono, desaparecesse a sedução do fantasma feminino.

Em suma, esse processo visava revelar a implicação da vontade, desvendando primeiro o envolvimento do corpo, depois da imaginação, em seguida da sensibilidade, culminando com o domínio das representações e da vontade, que se traduz na ausência de sonhos eróticos e da polução noturna.

Foucault (1985) observa que a doutrina de domínio da sexualidade, que inicialmente foi criada para os monges, mais tarde passou a ser indicada a toda população. Esse fator contribuiu para que nas sociedades ocidentais se criasse uma visão negativa da sexualidade. Assim como Foucault, Rubin (1989) afirma que a teoria de domínio do perigo sexual originada nas tradições religiosas ocidentais foi, posteriormente, assumida pela medicina geral e pela psiquiatria. Tanto os tabus religiosos como as formas de controle da sexualidade desenvolvidas pela psiquiatria e pela medicina criaram uma fronteira imaginária entre o sexo bom, saudável, maduro, santo, legal e politicamente correto - no caso, na heterossexualidade, no matrimônio, em vista da procriação - e o sexo mau, perigoso, psicopatológico, infantil, condenável e obra do diabo, enfim todas as formas de exercício da sexualidade que não se enquadram na forma anterior. A fronteira imaginária parece levantar-se entre a ordem sexual e o caos. É uma espécie de temor de que, ao permitir a alguém cruzar a barreira, poderá ocorrer alguma catástrofe, razão, portanto, da teoria do domínio sexual (Foucault, 1993; Rubin, 1989).

Segundo Rubin (1989), a ideia da negatividade sexual desenvolvida pelo cristianismo tem adquirido uma vida própria, não dependendo somente da religião para sua sobrevivência. Existe uma inter-relação muito próxima entre as ideias do cristianismo e de outros setores da sociedade, em se tratando de uma visão restritiva da sexualidade. O cristianismo considera o sexo como algo perigoso, destrutivo, negativo, e as leis sobre os comportamentos sexuais incorporam a concepção religiosa de que o sexo é um pecado atroz, que merece castigos. Com isso, a sociedade cria uma hierarquia de valor sexual, e a medicina e a psiquiatria utilizam-se dos tabus religiosos sobre a sexualidade para intervir na forma de desejos considerados incorretos. Esse conjunto de influências mútuas cria uma fronteira imaginária entre o sexo "bom" e o sexo "mau". Tanto o cristianismo como a psiquiatria e a medicina compreendem que a sexualidade deve adaptar-se a um único modelo. Essa percepção da sexualidade pode ser percebida na forma como a Igreja Católica atual tenta normatizar a sociedade no que se refere a tal tema. Surge daí a questão: como a herança dessa histórica concepção de sexualidade se faz notar nos posicionamentos da Igreja Católica na atualidade, quando entra em cena a AIDS?

\section{Catolicismo atual e sexualidade (século XX)}

Nas últimas décadas tem se intensificado a produção de análises sobre a influência dos discursos religiosos oficiais da Igreja Católica sobre o exercício da sexualidade e temas a ela relacionados. Entre essas análises destacam-se as de Almeida et al. (1992), Azzi (1983), Camargo (1975), Pierucci (1978), Nunes (1994), Ribeiro (1994). Nelas fica evidente que as ideias religiosas estão presentes tanto no embate pela descriminalização do aborto como nas lutas pelo exercício dos direitos reprodutivos e sexuais.

Os posicionamentos da Igreja Católica na atualidade, quando se referem às causas da AIDS ou às formas de prevenção, ancoram-se em sua tradicional concepção negativa e restritiva da sexualidade. Isto pode ser percebido em documentos do século XX em que a Igreja Católica explicita sua doutrina sobre a sexualidade: Sexualidade Humana, Verdade e Significado (1996), Familiaris Consortio (1981, n. 11, 14, 21, 36, 37, 66), Evangelium Vitae (1968, n. 97), Carta às famílias $(1994$, n. 7, 8, 12, 13, 14, 16), Catecismo da Igreja Católica (1992, n. 1632, 1900, 2337, 2339, 2349, 2360), Gaudium et Spes (Conc. Ecum. Vat. II, n. 22, 49), Lumen Gentium (Conc. Ecum. Vat. II, N. 11), Orientações educativas sobre o amor humano (1983, n. 4, 6).

No caso da Igreja Católica no Brasil, os pronunciamentos mais recentes da Conferência Nacional 
dos Bispos do Brasil (CNBB) sobre a sexualidade revelam que o episcopado brasileiro mantém firmes as proposições vindas do Vaticano sobre o tema. Nem a seriedade de questões como a AIDS faz com que a Igreja Católica reavalie suas posições. Em um de seus pronunciamentos, os bispos, após avaliarem a gravidade da situação causada pelo "flagelo da AIDS", a partir dos ensinamentos da Igreja, declaram: "é nosso dever alertar que o uso do sexo fora do matrimônio é irresponsável, fere a dignidade da pessoa humana, é contrário à Lei do divino Senhor da Vida e, portanto, é pecado que deve ser evitado" (CNBB, 1994).

Em outro pronunciamento, a CNBB, após afirmar que o contágio do vírus da AIDS não ocorre somente através do ato sexual, reafirma que, em sua atuação junto aos grupos de risco, a Igreja

mostra o valor da sexualidade, assumida de maneira consciente e integrada na realização pessoal, dentro de critérios éticos, tanto de seu uso como de sua abstinência, em vista do valor da vida, do respeito ao outro e da expressão de verdadeiro amor. E aponta o amor conjugal, vivido na fidelidade mútua, como o ideal para a plena comunhão de vida entre homem e mulher, conforme o plano do Criador. (CNBB, 1992, p. 67)

As consequências dessa forma de intervenção constituem um relativo impedimento à divulgação e à aceitabilidade de métodos preventivos eficazes. No entanto, como afirmamos anteriormente, os discursos da Igreja Católica não são unívocos. Eles variam de acordo com a diocese, com o bispo e seu viés progressista. Um exemplo dessa diversidade é o posicionamento de D. Paulo Evaristo Arns, ao dizer que o preservativo era um mal menor em relação à morte por infecção com o HIV. Além disso, vale lembrar que também não é porque o indivíduo se declara católico que deve aceitar todos os dogmas da Igreja, até mesmo porque muitos pensam criticamente sobre suas crenças (Parker, 2004).

Os discursos católicos sobre a AIDS são ambíguos, ou seja, quando se referem às causas da aquisição do vírus e aos métodos de prevenção, ela insere seus discursos na perspectiva de sua tradicional concepção restritiva e negativa da sexualidade. No entanto, quando se referem às formas de cuidado com os portadores do vírus, seguem a dinâmica de sua concepção de solidariedade e acolhida. Esse posicionamento pode ser percebido nas respostas baseadas nos princípios de fé e solidariedade da Igreja Católica, que é responsável pela criação de vários espaços de acolhimento e de apoio aos soropositivos.
A Igreja Católica se mostrou mais ativa na criação e manutenção de espaços de apoio a portadores de HIV e a seus familiares nos anos 90 , já na segunda década da epidemia. Nesse período iniciou-se o que D. Paulo Evaristo Arns denominou como "resposta samaritana" (Arns, 1990, p. 77), uma resposta cristã de amor e compaixão àqueles afetados pela AIDS, seus familiares, seus amigos, bem como às equipes prestadoras de assistência. Começou então a implementação das casas de apoio e o atendimento domiciliar para pessoas com HIV/AIDS. Em junho de 2000, bispos, padres, diáconos, religiosos(as), agentes de pastorais e líderes de ONG estiveram reunidos em Itaici, município de Indaiatuba (SP), com o objetivo de traçar estratégias para o enfrentamento da epidemia de AIDS. Esse encontro, promovido pela Comissão Nacional de DST/AIDS da Pastoral da Saúde, gerou a Carta de Itaici, na qual a Igreja Católica do Brasil posicionou-se claramente a favor de atitudes em benefício dos menos favorecidos acometidos pela doença (Andrade et al., 2007, p. 15).

Questiona-se então: que lugar ocupam os posicionamentos da Igreja Católica, enquanto fornecedora de significados e ordenadora das concepções de sexualidade e de AIDS e das práticas sociais associadas a essas concepções? Se são esses os posicionamentos da Igreja Católica - considerando as mudanças por que passam os campos religioso e cultural no Brasil atual, tendo o indivíduo e sua liberdade de escolha como centro e não a fidelidade à tradição das instituições religiosas -, como os fiéis reagem quando recebem o diagnóstico de que são portadores do HIV?

\section{Relação indivíduo-religião-AIDS}

Como afirmamos anteriormente, os discursos da Igreja Católica sobre a AIDS seguem a lógica de sua concepção negativa da sexualidade, podendo com isso prejudicar as campanhas de divulgação de métodos de prevenção do vírus HIV. Para verificar a incidência desses discursos na significação da AIDS por portadores do vírus, realizamos uma investigação empírica, no ano de $2009,{ }^{3}$ com pacientes de um hospital público e de uma clínica privada especializada em Infectologia, ambos localizados em Goiânia. Dentre um total de aproximadamente 50 pacientes que se declararam católicos, foram selecionados, por sorteio, 20 (14 homens e 6 mulheres). Entre estes, um homem e uma mulher eram divorciados; 8 homens e 2 mulheres eram solteiros, 4 homens e 4 mulheres

3. Esta investigação foi realizada por Raimundo Nonato Leite Pinto (2010), para sua dissertação de Mestrado, realizada sob minha orientação. Informo, no entanto, que a análise deste pesquisador destacou outros aspectos do material coletado, sendo, portanto, as afirmações aqui feitas de minha inteira responsabilidade. 
eram casados. Todos estavam em acompanhamento com o pesquisador, que é médico infectologista. O instrumento utilizado foi a entrevista individual, do tipo semiestruturada, que contou com o recurso de um questionário com quatro perguntas abertas, que procuraram identificar os significados conferidos pelos entrevistados à sua doença, a forma como enfrentam o problema, seu conhecimento sobre religião e a importância que esta poderia ter na evolução da infecção pelo HIV.

No processo de análise do material coletado, percebemos que, se partíssemos do pressuposto de que as ideias religiosas sobre sexualidade, oriundas do catolicismo, tinham grandes influências na forma como os portadores do HIV significavam sua experiência enquanto tal, ela não se confirmava, pelo menos com a intensidade que supúnhamos. Ou seja, a grande maioria dos entrevistados não fez referências, na sua concepção de sexualidade, ao ideário dessa tradição religiosa, como pressuposto para suas significações da AIDS. Vejamos as respostas obtidas à questão "você tem uma explicação para a sua doença?": aviso de deus (7 afirmações); predestinação (2); arroubos da juventude; sexo sem prevenção; fatalidade (11). Apenas para exemplificar, transcrevemos algumas das afirmações que se alinham com o "aviso de Deus" para o fato de estarem com o vírus:

"O que a gente tem que passar... seria, assim, evolução do espírito". (26 anos, sexo masculino, solteiro)

"Ele [Deus] permitiu que viesse essa doença pra me resgatar pra vida". (48 anos, sexo feminino, divorciada)

"Eu acredito que há intervenção divina porque, me colocando nesta situação, Deus quis me dar uma sacudida e falar: 'ou! Presta atenção que existe gente do seu lado e existe um ser maior acima de você, que sou Eu'." (38 anos, sexo feminino, solteira)

Considerando que foram somente sete pessoas que seguiram essa lógica na forma de significar sua doença, entendemos que, além de representar uma minoria que apresenta ideias religiosas, as fontes dessas ideias não se restringem às explicitadas nos discursos da Igreja Católica. Ou seja, quando afirmam que a causa está em outras vidas, constituindo-se assim em uma forma de evolução do espírito, os entrevistados estão se referendando em tradições religiosas não católicas. Ponderamos, no entanto, que as sete respostas em foco (acrescente-se a elas as outras duas respostas que apresentam cunho religioso) não constituem um número insignificante, considerando o tom de "resgate", o que evidencia que a pessoa se julga em condição de pecado. Esse fator nos leva a inferir que, para elas, as transgressões sexuais podem ser consideradas pecado ou algo mau, estando, então, em consonância com os ensinamentos da Igreja Católica.

As outras respostas dos entrevistados à mesma pergunta seguiram na direção da (ir)responsabilidade individual na conduta da vida, o que traz consigo o dado de que as instituições religiosas - e dentre elas o catolicismo - estão inseridas em um processo de mudança sociocultural em cujo centro se encontra o indivíduo. Vejamos os significados conferidos à doença pelos outros 13 entrevistados ao se referirem às causas da doença: descuidos humanos, arroubos da juventude (48 anos, sexo feminino, divorciada); sexo sem prevenção (43 anos, sexo masculino, solteiro); abuso nas farras (46 anos, sexo masculino, casado); aventuras no mundo do sexo (64 anos, sexo masculino, casado).

Outras pessoas significam sua doença, entendendo-a como causada por uma fatalidade:

"Tinha que acontecer, aconteceu." (43 anos, sexo masculino, solteiro)

"Pensava em tudo na vida, um câncer, uma lepra, qualquer coisa, menos isso." (57 anos, sexo feminino, casada)

“Aconteceu, eu não esperava." (38 anos, sexo feminino, solteira)

"Eu acho que nós, cada um, o que temos que passar não vai ficar para outra pessoa." (52 anos, sexo feminino, casada)

Como vimos, entre os 13 entrevistados que atribuíram o fato de serem portadores do HIV aos arroubos da juventude, ao sexo sem prevenção, à fatalidade, dez afirmaram tachativamente que isso não tem nada a ver com Deus, ainda que a pergunta tenha sido feita diretamente. Os outros, ainda que com alguma ponderação, declararam a mesma coisa. Vejamos algumas respostas à pergunta "você acha que a sua doença tem alguma explicação divina?”:

"Não, este negócio de explicação divina, para mim, ela não existe. Eu acho que é, na minha credulidade, ela não tem nenhuma relação com uma explicação divina.” (43 anos, sexo masculino, solteiro)

“Não tem nada a ver não." (26 anos, sexo masculino, solteiro)

"Não, eu não acredito em nada divino ou espiritual." (53 anos, sexo masculino, divorciado)

Considerando que das 20 pessoas entrevistadas, apenas 7 fizeram alguma referência à vontade de 
Deus como explicação para o fato de estarem com o HIV, somos instigados a compartilhar, ainda que parcialmente, com a afirmação de Sanchis (1992, p. 36) de que a Igreja Católica "está perdendo o seu caráter de definidor hegemônico da verdade e da identidade institucional no campo religioso brasileiro".

A majoritária afirmação dos entrevistados de que a explicação para o fato de estarem com HIV não é divina, mas consequência das ações humanas, leva-nos a pensar nas afirmações de Hervieu-Léger (1999), para quem as instituições religiosas (e, entre elas, colocamos novamente o catolicismo) perdem importância no agir religioso contemporâneo, pois seus dogmas não são mais seguidos pelos fiéis, embora eles continuem a crer em seus símbolos. Para a autora, isso acontece porque a modernidade religiosa está embasada em dois pilares profundamente relacionados: a autonomia do indivíduo e a perda de poder e de controle da instituição/Igreja e, consequentemente, da tradição.

Antes a participação religiosa era predominantemente ligada à tradição, uma vez que era herdada pelos indivíduos. Atualmente, porém, a validação religiosa, em grande parte dos casos, está relacionada à escolha individual: "o indivíduo passa a deter e a exercer um poder de escolha em detrimento da aceitação naturalizada de parâmetros religiosos e culturais socialmente herdados" (Hervieu-Léger, 1999, p. 39). Há uma recomposição da religião sob novas formas, mas com a perda de controle dos grandes sistemas religiosos que abarcavam o todo social $(\mathrm{Ca}-$ murça, 2003, p. 63).

Entendemos que essa tendência de relativização do peso dado às normatizações religiosas na sociedade atual foi verificada em nosso campo empírico, quando os sujeitos de nossa investigação explicitaram os significados conferidos ao fato de serem portadores do HIV.

\section{Ideias conclusivas}

Ao longo de nossa análise consideramos a gravidade e a dinâmica das diferentes formas como a AIDS no Brasil é experienciada e significada pelos portadores do HIV e pela sociedade em geral. Percebemos que entre os aspectos dessa dinâmica está a dimensão religiosa tanto das pessoas infectadas pelo HIV quanto das instituições religiosas - mais notadamente da Igreja Católica - que disponibilizam seus discursos e desempenham práticas sociais referentes ao tema.

No decorrer de nossa investigação, realizamos uma busca das ideias religiosas sobre sexualidade, oriundas da tradição judaico-cristã, que aparecem nos discursos da Igreja Católica, nos quais se percebemos a presença de uma concepção funcional da sexualidade restrita à procriação. Ao analisá-los na perspectiva de Foucault, fica claro que a doutrina de domínio da sexualidade, que inicialmente foi criada para os monges, passou, mais tarde, a ser indicada para toda a população. Esse fator contribuiu para que nas sociedades ocidentais se criasse uma visão negativa da sexualidade.

Segundo Rubin (1989), os tabus religiosos e as formas de controle da sexualidade desenvolvidas pela psiquiatria e pela medicina criaram uma fronteira imaginária entre o sexo bom (considerado saudável, maduro, santo, legal e politicamente correto) e o sexo mau (julgado como perigoso, psicopatológico, infantil, condenável e obra do diabo). Até hoje essas ideias permanecem nos pronunciamentos oficiais da Igreja Católica no Brasil, quando se referem à AIDS. Assim, nem a gravidade da presença da AIDS fez com que a Igreja Católica revisse sua concepção funcional da sexualidade. Os posicionamentos da Igreja Católica na atualidade em relação a AIDS refletem seus posicionamentos acerca da sexualidade. Constata-se, porém, uma ambiguidade: por um lado, quando se refere às causas da AIDS ou às formas de prevenção, ancora-se em sua tradicional concepção negativa e restritiva da sexualidade, podendo com isso prejudicar as campanhas de divulgação de métodos de prevenção do vírus HIV; por outro, com base na sua tradição da prática da solidariedade, institui a prática da acolhida dos portadores do HIV. Neste último caso, pode representar para os portadores tanto um consolo (não estão sós) quanto um reforço do ideário católico sobre a forma e o lugar legítimo para as práticas sexuais: a castidade ou o âmbito interno da família monogâmica.

Esse posicionamento, ainda que reverta em bem para os soropositivos (sentem-se acolhidos e apoiados), pode representar também um outro meio de controle e de normatização da sexualidade, aproximando-se daquilo que Fernandes (2007) denomina "homofobia cordial". Referindo-se às pastorais evangélicas que acolhem homossexuais com o intuito de convertê-los à heterossexualidade, Fernandes afirma que essa é uma das formas de discriminação que segregam indivíduos marcados como diferentes e inferiores, aproximando-os daqueles que exercem posição de superioridade moral, em uma relação de assujeitamento.

Pelo que pudemos perceber em nossa investigação, o efeito das casas de acolhida para portadores de HIV construídas pela Igreja Católica pode, de fato, se aproximar do que é produzido pelas pastorais das igrejas evangélicas no que tange aos homossexuais: uma relação assimétrica que pode implicar o engajamento emocional dos sujeitos envolvidos, favorecendo a perpetração de formas muito sutis de sujeição, violência e normatização de suas vidas. 
Assim, diferentemente de nossa suposição inicial, em que acreditávamos que a presença das ideias religiosas católicas nas representações da doença trouxesse consigo a sensação de culpa e de punição aos portadores do HIV, porque suas práticas sexuais não se inseriam na perspectiva dos discursos da Igreja Católica. No entanto, embora estando presente como referência de significados ao fato de ter-se tornado portador do vírus para um significativo número de entrevistados, isso não ocorre para a maioria deles. A partir desse dado, entendemos que os discursos religiosos referentes à AIDS, relacionando-a a uma con- cepção restritiva da sexualidade, não recebem adesão incondicional. As mudanças que estão ocorrendo no seio da cultura, no sentido de relativizar o peso dado às instituições religiosas, e a presença de uma maior centralidade e confiabilidade no potencial do indivíduo influenciam na recepção e adesão aos discursos religiosos sobre o tema em foco. Esse fator pode representar menor sofrimento aos portadores do vírus, uma vez que eles experienciam essa realidade com menor culpa do que se assumissem integralmente as restrições referentes às diferentes práticas sexuais presentes nos discursos religiosos.

\section{Referências}

ALMEIDA, Ângela Mendes de et al. Pensando a família no Brasil: da colônia à modernidade. Rio de Janeiro: Espaço e Tempo, 1992.

ANDRADE, Maria de Fatima de Olliveira et al. Casa Siloé: a história de uma ONG para crianças portadoras de HIV/AIDS. Historia, Ciência, Saúde, v. 14, n. 4, p. 187-212, 2007.

ARIÈS, Philippe. O amor no casamento. In: ARIÉS, Philippe; BÉJIN, André (Orgs.). Sexualidades ocidentais: contribuições para a história e para a sociologia da sexualidade. Tradução de Lygia Araújo Watanabe e Thereza Christina F. Stummer. São Paulo: Brasiliense, 1985a.

ARIÉS, Philippe. São Paulo e a carne. In: ARIÉS, Philippe; BÉJIN, André (Orgs.). Sexualidades ocidentais: contribuições para a história e para a sociologia da sexualidade. Tradução de Lygia Araújo Watanabe e Thereza Christina F. Stummer. São Paulo: Brasiliense, 1985b.

ARNS, Paulo Evaristo. Enfrentando a aids em São Paulo. In: INSTITUTO DE ESTUDOS DA RELIGIÃO. Igrejas e aids: perspectivas bíblicas e pastorais. Rio de Janeiro: ISER, 1990.

AZEVEDO, Thales. Catolicismo no Brasil. Petrópolis: Vozes, 1969.

AZEVEDO, Thales. Problemas metodológicos da sociologia do catolicismo. In: AZEVEDO, Thales. Cultura $e$ situação racial no Brasil. Rio de Janeiro: Civilização Brasileira, 1966.

AZZI, Riolando. Moral católica e sociedade colonial. Rio de Janeiro: Centro João XXIII, 1983. Mimeo.

AZZI, Riolando. Elementos para a história do catolicismo popular. REB, v. 141, n. 36, p. 95-130, 1976.

BRANDÃO, Carlos Rodrigues. Ser católico: Dimensões brasileiras: um estudo sobre a atribuição da religião. In: FERNANDES, Rubem César et al. (Org.). Brasil \& EUA: religião e identidade nacional. Rio de Janeiro: Graal, 1988. BRASIL. Ministério da Saúde. Boletim epidemiológico Aids. Brasília, v. 13, n. 2, p. 45, 2000.
BRAUNSTEIN, Philippe. Abordagens da intimidade nos séc. XIV a XV. In: DUBY, Georges (Org.). História da vida privada. Tradução de Maria Lúcia Machado. São Paulo: Companhia das Letras, 1995.

CAMARGO, Cândido Procópio Ferreira de. Catolicismo e família no Brasil contemporâneo. Estudos CEBR AP, São Paulo, v. 12, 1975.

CAMURÇA, Marcelo Ayres. Secularização e reencantamento: a emergência dos novos movimentos religiosos. $B I B$, n. 56, p. 55-69, 2003.

COMBLIN, José. Para uma tipologia do catolicismo no Brasil. REB, v. 28, n. 1, p. 46, 1968.

DUBY, Georges. A solidão nos séc. XI a XIII. In: DUBY, Georges (Org.). História da vida privada. Tradução de Maria Lúcia Machado. São Paulo: Companhia das Letras, 1995. FERNANDES, Luis Osvaldo Ribas Lobos. Homofobia cordial. Salvador: UNEB/ Diadorim, 2007, mimeo.

FLANDRIN, Jean-Louis. A vida sexual dos casados na sociedade antiga: da doutrina da Igreja à realidade dos comportamentos. In: ARIÉS, Philippe; BÉJIN, André (Orgs.). Sexualidades ocidentais: contribuições para a história e para a sociologia da sexualidade. Tradução de Lygia Araújo Watanabe e Thereza Christina F. Stummer. São Paulo: Brasiliense, 1985.

FLANDRIN, Jean-Louis. O sexo e o Ocidente. Tradução de Jean Progin. São Paulo: Brasiliense, 1988.

FOUCAULT, Michel. A ordem do discurso: aula inaugural no Collège de France, pronunciada em 2 de dezembro de 1970. São Paulo: Loyola, 2001.

FOUCAULT, Michel. História da sexualidade I: a vontade de saber. Tradução de Maria Tereza da C. Alburquerque e J. A. Guilhon Alburquerque. 11. ed. Rio de Janeiro: Graal, 1993.

FOUCAULT, Michel. História da sexualidade II: o uso dos prazeres. Tradução de Maria Tereza da C. Alburquerque e J. A. Guilhon Alburquerque. 7. ed. Rio de Janeiro: Graal, 1994. 
FOUCAULT, Michel. O combate da castidade. In: ARIÉS, Philippe; BÉJIN0, André (Org.). Sexualidades ocidentais. São Paulo: Brasiliense, 1985.

GIDDENS, Anthony. A transformação da intimidade: sexualidade, amor e erotismo nas sociedades modernas. Tradução de Magda Lopes. São Paulo: Ed. Unesp, 1993.

GRIECO, Sara F. Matthews. O corpo, aparência e sexualidade. In: In: DUBY, Georges; PERROT, Michelle (Orgs.). História das mulheres: do Renascimento à Idade Moderna. v. 3. Porto: Afrontamento, 1991.

HERVIEU-LÉGER, Danièle. La religion pour memoire. Paris: Cerf, 1993.

HERVIEU-LÉGER, Danièle. Representam os surtos emocionais contemporâneos o fim da secularização ou o fim da religião?. Religião e Sociedade, v. 18, n. 1, p. 31-48, 1997.

HERVIEU-LÉGER, Danièle. O peregrino e o convertido. Tradução de João Batista Kreuch. Petrópolis: Vozes, 1999. KESSEL, Elisja Sculte. Virgens e mães entre o céu e a terra. In: DUBY, Georges; PERROT, Michelle (Orgs.). História das mulheres: do Renascimento à Idade Moderna. v. 3. Porto: Afrontamento, 1991.

LEAL, Andréa Fachel. Panorama da AIDS no Brasil. Entrevista publicada pelo CLAM em 9 dez. 2009. Disponível em: <http://www.clam.org.br/publique/cgi/cgilua.exe/sys/ start.htm?infoid=6213\&sid=43>. Acesso em: 7 jun. 2010.

LECLERCQ, Paulette L'Hermite. A ordem feudal (séculos XI-XII). In: DUBY, Georges; PERROT, Michelle (Orgs.). História das mulheres: a Idade Média, v. 2. Porto: Afrontamento, 1990.

NUNES, Maria José Fontelas Rosado. De mulheres, sexo e igreja: uma pesquisa e muitas interrogações. In: COSTA, Albertina de Oliveira; AMADO, Tina (Orgs). Alternativas escassas: saúde, sexualidade e reprodução na América Latina. São Paulo: Fundação Carlos Chagas ; Rio de Janeiro: Ed. 34, 1994.

PARKER, Richard. Corpos, prazeres e paixões: a cultura sexual no Brasil contemporâneo. São Paulo: Best Seller, 1991. PARKER, Richard. Diversidade sexual, análise sexual e a educação sexual sobre a Aids no Brasil. In: LOYOLA, Maria Andréa (Org.). Aids e sexualidade: o ponto de vista das ciências humanas. Rio de Janeiro: Relume-Dumará, 1994. PARKER, Richard. O vírus da aids contaminou o casamento. O Estado de S. Paulo, São Paulo, 6 dez. 2004. Entrevista concedida a Mônica Manir. Disponível em: <http://www.hiv.org.br/internas_materia.asp?cod_secao $=$ acontece $\&$ cod_materia $=762>$. Acesso em: 7 jun. 2010.

PIERUCCI, Antônio Flávio de Oliveira. Igreja: contradições e acomodação - ideologia do clero católico sobre a reprodução humana no Brasil. São Paulo: Brasiliense, 1978.

PIERUCCI, Antonio Flávio; PRANDI, Reginaldo. A realidade social das religiões no Brasil. São Paulo: Hucitec, 1996. PINTO, Raimundo Nonato Leite. Religião e saúde: o caso de portadores do vírus da imunodeficiência humana HIV/ Aids. 2010. Dissertação (Mestrado) - Programa de Pós-
-Graduação em Ciências da Religião, Pontifícia Universidade Católica de Goiás, Goiânia, 2010.

RIBEIRO, Lúcia. Anticoncepção e comunidades eclesiais de base. In: COSTA, Albertina de Oliveira; AMADO, Tina (Orgs.). Alternativas escassas: saúde, sexualidade e reprodução na América Latina. São Paulo: Fundação Carlos Chagas; Rio de Janeiro: Ed. 34, 1994.

RUBIN, Gayle. Reflexionando sobre el sexo: notas para una teoría radical de la sexualidad. In: VANCE, Carol (Org.). Placer e peligro: explorando la sexualidad feminina. México: Revolución, 1989.

SANCHIS, Pierre. Catolicismo: unidade religiosa e pluralismo cultural. São Paulo: Loyola, 1992.

SCOTT, Joan. Gênero: uma categoria útil para análise histórica. Recife: SOS Corpo, 1996.

STEIL, Carlos Alberto; HERRERA, Sonia Reyes. Catolicismo e ciências sociais no Brasil: mudanças de foco e perspectiva num objeto de estudo. Sociologias, Porto Alegre, n. 23, p. 354-393, 2010.

THOMASSET, Claude. Da natureza feminina. In: DUBY, Georges; PERROT, Michelle (Orgs.). História das mulheres: a Idade Média, v. 2. Porto: Afrontamento, 1990. VECCHIO, Silvana. A boa esposa. In: DUBY, Georges; PERROT, Michelle (Orgs.). História das mulheres: a Idade Média, v. 2. Porto: Afrontamento, 1990. In: DUBY, Georges; PERROT, Michelle (Orgs.). História das mulheres: a Idade Média, v. 2. Porto: Afrontamento, 1990.

\section{Documentos da Igreja Católica}

CELAM (Conferência Episcopal Latino-Americana). Documento final da comissão, n. 2: Família e Demografia. SEDOC, v. 6, n. 5, 1968.

CNBB (Conferência Nacional dos Bispos do Brasil). Diretrizes gerais da ação pastoral da Igreja no Brasil: 2003-2006. São Paulo: Paulinas, 2000. (Documentos da CNBB, 71).

. Em favor da família, 20 mar. 1975. SEDOC, v. 8, n. 84, 1975.

A Igreja e a AIDS. Documentos da Presidência $e$ CEP, n. 58, 1992. Disponível em: <http://www.divinoespiritosanto. org/cnbbdoc58.htm>. Acesso em: 15 jul. 2010.

. A serviço da vida e da esperança, 1994. Documentos da CNBB, n. 58, 1997.

Nota da Secretaria-Geral a propósito do projeto de lei de união civil de pessoas do mesmo sexo, 1996. Documentos da CNBB, n. 58, 1997.

Pronunciamento sobre a família, 1996. Documentos da CNBB, n. 58, 1997.

CONCÍLIO ECUMÊNICO VATICANO II. Constituição Pastoral Gaudium et Spes. Petrópolis: Vozes, 1996.

Constituição dogmática sobre a Igreja Lumem Gentium. Petrópolis: Vozes, 1996.

CONGREGAÇÃO PARA A EDUCAÇÃO CATÓLICA. Orientações educativas sobre o amor humano. São Paulo: Paulinas, 1983. 
CONSELHO PONTIFÍCIO PARA A FAMÍLIA. Sexualidade humana: verdade e significado. São Paulo: Paulinas, 1996.

O ano da família. SEDOC, v. 7, n. 73, 1974.

. A função da família hoje. Discurso aos participantes da VIII Sessão do Conselho- Geral da Pontifícia Comissão para a América Latina. SEDOC, v. 8, n. 87, 1975. JOÃO PAULO II. Exortação Apostólica Familiaris Consortio. Petrópolis: Vozes, 1981.

. Carta às famílias Gratissimam Sane. São Paulo: Paulinas, 1994.

. A missão da família cristã no mundo de hoje. São Paulo: Paulinas, 1982.

\section{2.}

.Catecismo da Igreja Católica. São Paulo: Paulinas,

PAULO VI. A função da família hoje. Discurso aos participantes da VIII seção do Conselho-Geral da Pontifícia Comissão para a América Latina, 29 out. 1975. SEDOC, v. 87, n. $8,1975$.

O ano da família. Discurso aos membros da Comissão Pontifícia para a Família, 13 mar. 1974. SEDOC, v. 73, n. 7, 1974.

Carta encíclica Evangelium Vitae. São Paulo: Paulinas, 1968.

PIO XII. Discurso à frente da família e à Federação das Associações das Famílias Numerosas. REB, v. 12, n. 1, 1952.

\title{
Catholicism, sexuality and AIDS: to believe without belonging, belonging without being faithful
}

\begin{abstract}
In this article we consider the intricate relation between: a) the dynamics acquired with the advance of HIV in the current society, b) the different conceptions of sexuality that people's sexual practices mean and the adhesion or not to the measures put forth about the necessary care for the prevention of Aids, c) the permanencies and changes in the religious field, where the presence of a standardizing speech on sexuality is observed, mainly from the Catholic Church, d) the characteristic of the centralization of the individual as an instance of reference in the current culture. We analyze how these aspects are articulated in the way HIV carriers attribute meaning to this reality.
\end{abstract}

Key words: Catholic Church, sexuality, AIDS, individual, religious field.

\section{Catolicismo, sexualidad y SIDA: pertenecer sin ser fiel}

\section{Resumen}

Consideramos en este artículo la relación intrincada entre: a) la dinámica adquirida por el avance del VIH en la sociedad actual, b) los diversos conceptos de la sexualidad que significan las prácticas sexuales de la gente y la adherencia o no a las ofertas cuánto a los cuidados necesarios a la prevención del SIDA, c) las permanências y cambios ocorridos en el campo religioso, donde si observa la presencia de un discurso normatizador de la sexualidad, principalmente de la iglesia católica, d) la característica del centralidade del individuo como referencia en la cultura actual. Analizamos como estos aspectos se articulan en la manera como los portadores del VIH significan esta realidad.

Palabras clave: Iglesia Católico, sexualidad, SIDA, individuo, campo religioso.

Data de recebimento do artigo: 20/6/2010

Data de aprovação do artigo: 3/8/2010 